\title{
ENSAIO SOBRE PRÁTICAS COSMOPOLÍTICAS ENTRE FAMÍLIAS WAJÃPI: SOBRE A IMAGINAÇÃO, O SENSÍVEL, O XAMANISMO E OUTRAS OBVIEDADES
}

\author{
Joana Cabral de Oliveira
}

\begin{abstract}
Eu abordei as ideias elementares acerca da epistemologia, isto é, acerca de como nós podemos conhecer qualquer coisa. No pronome nós, obviamente, eu incluo a estrela do mar, a floresta de sequoias, a segmentação do ovo e o Senado dos Estados Unidos

Gregory Bateson (1979:04).
\end{abstract}

A presa era carregada nas costas, o peso era grande. Admirando aquela cena, perguntávamos em silêncio como ela conseguia suportar tamanha carga em ombros tão estreitos. A trilha era acidentada: troncos enormes a ultrapassar, subidas íngremes... Por vezes abandonava o cadáver no chão, escrutinava o trajeto e voltava para buscá-lo, seguindo a melhor rota. A impressão era que aquela caminhada duraria uma eternidade.

Foi sentada em uma árvore caída na floresta que eu e Ajãreaty observamos próxima aos nossos pés a formiga que transportava uma mutuca morta. Ela vinha solitária em seu caminho. Com a presa sobre o lombo, subia encostas de folhas, descia por galhos que emergiam como montanhas e passava arduamente por toda sorte de matéria orgânica que forma o típico solo de uma floresta de terra firme. Ajãreaty quebrou o silêncio: "Dever ser tapi 'irã [anta] para ela [a formiga], né, si'ã [filha]?! Porque é muito grande e pesado para ela, né, si'ã!?".

\section{Circunscrição etnográfica}

Esta cena, desenrolada em uma estadia de campo na Terra Indígena Wajãpi (TIW), faz parte do material etnográfico coletado ao longo de pesquisas sucessivas $^{1}$ junto a falantes de wajãpi ${ }^{2}$ que habitam a bacia do rio Jari (AP). 
Ajãreaty e sua família foram algumas das pessoas que me conduziram por esse universo ameríndio. Mulher de meia idade, já considerada uma avó (sa'i), ela foi casada com um grande chefe. Após seu falecimento, Ajãreaty assumiu gradualmente os atributos de chefia e hoje é uma importante rota de relação para os brancos que chegam por lá. Ela pertence ao grupo local Inipuku wanã kõ. Wanã kõ, "aqueles que vivem juntos" (Gallois 1986:57), é uma das bases da estrutura social wajãpi, que está ligada à ocupação territorial dispersa e à sua constante dinâmica de migração. Conforme Gallois: "[...] o povo Wajãpi dissolve-se numa série de unidades territoriais independentes, não integradas politicamente" (1986:57).

Apesar de este ser um ponto central de minha inserção em campo, ele não foi o único. Passei por algumas das 50 aldeias espalhadas pela TIW e convivi com famílias de diferentes grupos locais. Nessas ocasiões, registrei pequenos atos de enunciação e ação (tal como a cena de abertura), que se somam às inúmeras conversas com aqueles que me receberam em suas moradas, fornecendo ensinamentos, comidas e cuidados.

Etnografias anteriores na mesma região (Gallois 1988; Campbell 1989), bem como sobre outros grupos locais wajãpi, que atualmente estão na calha do rio Oiapoque na Guiana Francesa (Grenand 1980), já pontuavam uma característica marcante da cosmologia deste grupo: concebe-se um cosmos formado por uma sobreposição de platôs, cujo patamar terrestre, onde vivemos, é ocupado por uma miríade de seres com os quais a humanidade wajãpi precisa negociar constantemente a produção da vida. Por este motivo, atividades elementares - tais como a coleta, a caça e a derrubada de porções de floresta para a preparação de roçados e aldeias (sempre construídas dentro de uma roça, um espaço amansado através do afastamento dos seres que habitam a mata) — são reguladas por interditos e cuidados de diversas ordens, os quais são orientados pela necessidade de negociação com os demais moradores do estrato terrestre (animais, plantas, rochas, rios, montanhas etc. e seus respectivos donos cosmológicos - ijarã).

Ao descrever as formas de nominação e relação dos Wajãpi da Guiana com animais e vegetais, Pierre Grenand (1980) insiste que tais interações se dão por meio de um idioma social: trata-se de relações sujeito com sujeito. Por meio de etnografia minuciosa, Grenand chega à seguinte conclusão: "Assim, para o homem, o animal é um animal e, para o animal, o homem é um animal" (1980:42) — proposição que gera uma série de cuidados na lida com a caça. Temos aqui uma fórmula que lembra aquela que ficou famosa no final dos anos 1990 com o trabalho de Tânia Stolze Lima (1996) sobre uma caçada de porcos entre os Yudjá e a consequente elaboração do perspectivismo ameríndio por Viveiros de Castro $(2002)$ e Lima $(1996,2005)$. 
É nesse cenário que este artigo se constitui. Contudo, busca-se olhar para o que está à margem do epicentro da referida discussão, isto é, fora do escopo da caça, da guerra e do xamanismo. Ao dedicar atenção às ações que se desenrolam nos roçados, pátios e nas incursões familiares pela floresta (acompanhando sempre uma rota feminina, dada a separação de gênero que se impôs à pesquisadora), uma questão que emergiu foi: o que se pode dizer sobre as interações e os eventos de conhecimento que se travam entre distintos tipos de seres fora da operacionalização de um xamanismo concentrado e das relações de predação?

Elementos para responder a esta questão podem ser notados em muitas etnografias. Entre os Achuar, por exemplo, Taylor (2001) mostra como os cantos anent (que são de amplo domínio) são proferidos para elaborar boas roças, para ter sucesso na caça, para amansar xerimbabos e para seduzir cônjuges. Overing (2006) descreve como para os Piaroa as relações entre processos sensoriais é importante para lidar com uma rede cósmica. Entre os Jarawara, Maizza (2014) aborda como ações de sedução e cuidado, presentes na criação de filhos e no casamento, são replicadas na lida com as plantações que, para crescerem vistosas, precisam ouvir as palavras de seus donos e se sentirem olhadas. Ao abordar o tema da construção de parentes em diversos contextos etnográficos, autoras como Souza (2004), Vilaça (2002) e Rival $(2001,1993)$ apresentam como cuidados cotidianos, que não estão relacionados a uma potência xamânica autoevidente, se fazem presentes na produção de consanguíneos e em processos de crescimento, tecendo-se um densa rede de relações entre humanos e diferentes tipos de seres. Mas, sem dúvida, é o trabalho de Eduardo Kohn (2013) que parece tocar nesta questão de modo incisivo e exaustivo. Ao propor sua "antropologia para além do humano", ele toma a etnografia runa para descrever circuitos comunicacionais entre humanos e não humanos que não recorrem necessariamente às ações xamânicas.

\section{Questões imanentes}

A cena de abertura é um bom exemplo do material que compõe essa etnografia minimalista; acontecimento corriqueiro, talvez banal, ele foi um dos motes que inspiraram este ensaio sobre os modos ordinários de alguns wajãpi conhecerem outros mundos. Talvez pareça de pronto ao leitor que Ajãreaty apenas lançava mão de uma recursividade metafórica, de uma representação que dá sentido ao mundo. Porém, esse evento não deve ser compreendido em si mesmo. Ao longo do artigo serão somadas outras descrições que visam 
sustentar a opção analítica tomada. A aposta é que vale a pena alinhar-se com uma crítica da noção de representação (Latour 2001; Viveiros de Castro 2002; Kohn 2013, entre outros autores) e ver como formulações deste tipo são mecanismos de constituição e expressão de um mundo próprio. ${ }^{3}$ Tratar tais enunciados, práticas e ações como mera representação (metáfora ${ }^{4}$ de um mundo lá fora) é tornar o "mundo vivido" (Gow 2001) por essas populações algo menor, deixando ao Ocidente e à sua Ciência o privilégio de lidar com o real, com o mundo.

Se de imediato este primeiro mote remete ao perspectivismo ameríndio, a opção aqui é, todavia, tornar a reflexão lenta para seguir uma composição etnográfica que pretende dialogar com as noções de cosmopolítica de Isabelle Stengers (2005) e de comunicação de Gregory Bateson (1979, 1986), em seus possíveis rendimentos quando combinadas com a ideia lévi-straussiana de lógica do sensível (Lévi-Strauss 1970).

Em sua proposição cosmopolítica, Stengers apresenta algo mais próximo de uma atitude reflexiva do que de uma teoria ou explanação generalista. Nesse movimento, ela se aproxima da etnografia: "a proposta cosmopolítica [...] tem sentido apenas em situações concretas onde os praticantes a operam" (2005:994). A atitude por ela fomentada é a do riso com a teoria; é diminuir a velocidade e dar de ombros para a autoridade no sentido das grandes explicações, para ir ao encontro de reflexões imanentes ao campo. Movida por essa atitude e, sobretudo, inspirada pela etnografia, irei guiar-me por duas questões específicas que se articulam: como relações entre sujeitos humanos e não humanos se expressam e se efetuam fora do escopo das pessoas que têm pajé (para usar o termo tupi ao invés do tungúsico xamã)? E qual a possibilidade de pensar uma comunicação entre naturezas, ou melhor, uma passagem entre mundos, sem cair na unicidade do referente e, por consequência, no relativismo cultural?

O material que trarei aqui pode ser organizado em dois grandes blocos: um que se refere às relações cotidianas que pessoas "empajezadas" travam com os múltiplos sujeitos que povoam a plataforma terrestre; e outro sobre como os mundos desses diversos entes se dão a conhecer e se comunicam por procedimentos que, tal como na primeira cena, não passam pelo potente vértice das substâncias xamânicas. Com isso não se pretende criar uma simples oposição entre atividades xamânicas e não xamânicas, mas apenas evidenciar outro campo de relações de saber que, como será abordado, dialoga com o modo xamânico de conhecer. Delinear-se-á, dessa maneira, uma cosmopolítica que parece ser tecida a partir do sensível, da capacidade imaginativa e da comunicação entre mundos. Se o perspectivismo ameríndio tem como cerne "[...] duas características recorrentes na Amazônia: 
a valorização simbólica da caça e a importância do xamanismo" (Viveiros de Castro 2002:357), caminharemos aqui pelas zonas rarefeitas, tendo como ponto de partida a relação de pessoas "empajezadas" com as plantas algo que foi abordado em outros termos por Maizza (2014), Taylor (2001) e Rival (1993 e 2001).

\section{Outra floresta culta}

Em minha pesquisa sobre a relação de famílias wajãpi com os vegetais, cujo interesse era etnografar modos de conhecer os espaços onde eles se situam - os domínios da roça $(k o o)$ e da floresta $\left(k a^{\prime} a\right)$ - as plantações e os artefatos de seres aparentemente não humanos ganharam proeminência. Há os cultivos de animais e espíritos que se espalham mata afora, tais como: $a^{\prime}$ y makure (tabaco de preguiça), so'o mani'y (maniva de veado), jurupari mani'y (maniva do espectro do morto), uwa kã'áe (pimenta do caranguejo), so'o mão (mamão de veado), anuja marakuia (maracujá de rato) etc. Há também os bens culturais que aparecem aos homens como vegetais: ãjã pina (anzol de ãja $\left.\tilde{a}^{5}\right)$, ajjã parapi (prato de ãjã), moju akãneta (cocar de sucuri), moi maraka (maraca de cobra), jãvi jyky (mingau de jabuti), kai jura (escada de macaco)... E, em menor incidência, os elementos da floresta dos outros, como a palmeira ãjã pino (bacaba de ãjã) e a pteridófita tajau rõpa (palha de queixada).

A lista dos vegetais que são artefatos, plantações ou mesmo frutos coletados por animais e espíritos e que veem a si mesmos como humanos é longa. Se notarem, verão que me restringi até o momento à nomenclatura botânica wajãpi; os exemplos se estenderiam se incluísse as formas de enunciação contextuais ou mesmo os eventos de conhecimento, como aquele do primeiro mote. A aposta é que muito do que se conhece sobre a perspectiva de outrem é elaborado por meio de índices concretos ${ }^{6}$ (tal como a maniva do espectro do morto, o maracujá de rato, o prato de ãjã a anta da formiga etc.), que permitem imaginar mundos outros.

Olhando cuidadosamente esse conjunto de plantas, notei que a lógica do sensível (Lévi-Strauss 1970) aparecia como grande operador. As plantações de animais e espíritos são botanicamente muito semelhantes aos cultivares wajãpi, e seus artefatos apresentam traços morfológicos evidentes em relação aos bens culturais. Este aspecto operacional também pode ser exemplarmente observado na cena de abertura. Ajãreaty realiza comparações e correspondências que permitem a ela imaginar que a "mutuca deve ser anta para a formiga": a relação caça-presa se replica entre os termos 
mutuca-formiga e anta-wajãpi, e a proporção entre o peso e o tamanho da presa mutuca para a formiga em comparação com a presa anta para um wajãpi é sensivelmente equivalente.

Vale notar que a anta tem grande relevância nesse contexto etnográfico; é a maior caça e um importante índice de proporções excessivas que está presente em diversas formulações, prestando-se inclusive como classificador: nãnã tapi'irã (abacaxi-anta) tem frutos maiores do que o comum; asikaru tapi'irã (cana-anta) é reconhecida pela grossura de seus doces caules; yvyra tapi'irã (árvore-anta) apresenta dimensões colossais; tukura tapi'irã (grilo-anta) é o maior dos grilos; e o termo tapi 'irã é ainda jocosamente empregado para apelidar brancos obesos. Enfim, a anta, devido ao seu enorme peso (constatado pelos ombros daqueles que ajudam o caçador a transportar a presa abatida), à grande quantidade de carne (evidenciada pela farta distribuição entre parentes) e ao cheiro avassalador (sentido no momento de esquartejamento e limpeza dos intestinos), presta-se a qualificar tudo que é desmedidamente grande, tal como aquela mutuca para a formiga.

Para seguirmos com o argumento, evocarei outros atos enunciativos que permitem perceber as operações sensíveis traçadas por alguns wajãpi na tessitura de um saber sobre os mundos dos outros. Uma noite, na casa do velho chefe Waiwai, quando nos preparávamos para dormir, ele cuidadosamente ajeitou um velho tipiti que se encontrava sobre a minha rede, dizendo: "Ikatu tepisï jane aryvo, ajaire jurupari novãi, okyije! Moju ijupe" ["É bom ter tipiti sobre a gente, jurupari ${ }^{7}$ não chega, ele tem medo! É sucuri para ele"]. Tanto a atividade de constrição do tipiti como seu formato cilíndrico, suas texturas lisa e encerada (próprias à porção externa da casca do arumã), bem como os pequenos losangos desenhados pela trama lembram em muito o corpo de uma cobra, mas não de qualquer uma, mas sim da maior constritora das terras baixas da América do Sul - a sucuri. ${ }^{8}$

Para citar mais um exemplo singelo, quase banal se não guardasse alguma poesia, recorro a outro evento de conhecimento. Certa feita subia por um barranco lamacento na companhia de uma avó, e escorria por ele, devido à forte chuva, uma água que carregava uma lama branca e fina. Ao notar tamanha frivolidade, ela me disse: "Muru typy'o eu ijupe" ["Tapioca de [rã] muru dizemos para ela [a lama]"]. Sua textura e sua cor eram semelhantes às da fina goma da mandioca (a tapioca), e sua ocorrência, próxima ao rio e em meio às águas celestes, foi rapidamente associada a um ser de tal habitação - a rã muru. ${ }^{9}$

Sem dúvida o mais fácil seria, em resumo, atribuir todas essas operações ao perspectivismo ameríndio e assim o problema estaria resolvido antes de ser criado. Mas tornemos a reflexão lenta, como sugere Isabelle Stengers, perguntando o que mais se pode pensar a partir dessas formulações. 
O que se nota é que certas características sensíveis perpassam as diversas perspectivas: o formato cilíndrico e comprido do tipiti, sua textura e ação (constrição) são semelhantes ao corpo da sucuri, modo como o espectro do morto se relaciona com o que para os homens é um tipiti; a lama fina e esbranquiçada que se disse ser muru typy'o (tapioca de rã muru) tem a mesma textura e coloração do amido que se deposita no fundo dos panelões de tucupi; e assim por diante. A operacionalização da lógica do sensível atravessa as perspectivas.

Tal proposição talvez fique mais explícita se voltarmos um olhar minucioso às plantas dos outros, antes citadas. As semelhanças entre a bacaba (pino) e a ãjã pino (bacaba de ãjã) são evidentes: ambas as palmeiras possuem cachos formados por pedúnculos de um vermelho vibrante e frutos esféricos verdes, mas se distinguem quanto ao porte do pé e ao volume e à distribuição de frutos; ãjã pino não passa de um metro de altura e seu cacho tem pequenos carpos minguados. O maracujá (marakuja) e o anuja marakuja (maracujá de rato) são ambas trepadeiras herbáceas, de flores vistosas que têm estaminódios ${ }^{10}$ roxos, androginóforo ${ }^{11}$ esverdeado e desenvolvido, com uma corona ${ }^{12}$ no ápice, sendo o maracujá do rato relativamente menor, além de ter frutos pequenos e verdes. O mamoeiro (mão) e o so'o mão (mamão de veado) são parecidos quanto ao aspecto geral: arbóreo, provido de látex branco, com folhas lobadas sustentadas por longos pecíolos; quanto às partes reprodutivas, ambas são dotadas de flores pentâmeras brancas e de frutos de tipo baga, mas se distinguem quanto ao tamanho, os frutos do mamão de veado tendo por volta de três centímetros e o porte da árvore sendo menor.

As mesmas relações de similaridade concreta podem ser notadas nos bens culturais dos outros: ãjã pina (anzol de ãjã) é o nome dado a um arbusto que possui espinhos lenhosos em formato de anzol; o arbusto moi maraka (maracá de cobra) tem frutos bojudos e ovalados, com câmeras repletas de sementes esféricas, lembrando um pequeno maracá; o fungo tajau purure (enxada de queixada), conhecido por nós como orelha de pau, tem formato análogo ao da lâmina da enxada, achatado, reto na extremidade, que se fixa no tronco, e arredondado na borda oposta; a planta herbácea ãjã parapi (prato de ãjã) possui folhas orbiculares ${ }^{13}$ e levemente côncavas devido à inserção do pecíolo no meio da face inferior; a árvore denominada jãvi jyky (mingau jyky de jabuti) tem frutos carnudos de polpa branca que, caídos após a maturação, se desfazem em uma massa leitosa e viscosa, assemelhando-se à textura e à cor do mingau de goma de mandioca (jyky); e assim por diante.

São todas semelhanças imponentes, no sentido de que são aspectos sensíveis que atravessam os múltiplos mundos. Talvez possamos pensar que há passagens entre as diversas naturezas; não são mundos fechados, mas 
mundos que se comunicam, tal como pontua Lima (2002) para a diferença entre almas no caso yudjá (as almas não são pura comensurabilidade); de forma simétrica e invertida, chamo a atenção para um fundo de semelhança entre as corporalidades - talvez elas não sejam só diferença (pura incomensurabilidade). É essa comunicação entre naturezas que permite aos homens sem pajé vislumbrarem e, sobretudo, imaginarem (tomando a imaginação como um dispositivo de conhecimento) como os outros seres percebem e cultivam seus mundos.

\section{Imaginações}

Em seu trabalho, Stengers (2005) cunha um termo que é central para pensar a cosmopolítica: a etoecologia. A etoecologia aparece como uma condição de sua proposta analítica, pois ela remete à necessidade de que as coisas sejam pensadas a partir de um lugar e de um comportamento próprios. O saber está atrelado a uma posição no mundo ou, para usar um termo de Ingold (2000) que parece muito apropriado aqui, os sujeitos conhecem a partir de seu local de habitação. Dessa maneira, Stengers contrapõe-se à pretensão de um saber generalizante, que se pretende universal.

Para a questão aqui apresentada, o termo etoecologia é relevante, pois permite referir acuradamente ao saber daqueles que não são "empajezados" e que, por isso, não veem a enxada do queixada como enxada, mas sim como fungo, não sentem a tapioca da rã muru como tapioca, mas sim como lama... Em suma, produzem um saber a partir de seu local de habitação e da capacidade imaginativa para conhecer mundos outros através do concreto.

É importante pontuar que o sentido de cosmos atribuído por Stengers na composição do termo cosmopolítica se refere "[...] ao desconhecido, constituído por esses múltiplos mundos divergentes e pelas articulações das quais eles poderiam eventualmente ser capazes" (2005:995). Em seu argumento, o cosmos cumpre a função de alargar as possibilidades, incluindo o que nem sequer conhecemos; ele cria um espaço do desconhecido. O sensível, no recorte aqui realizado, somado à capacidade de imaginar a posição de outrem (de colocar-se virtualmente no local de habitação de uma rã, de um jabuti ou de um ãjã) permite relacionar-se com o desconhecido de maneira a tornar esse limbo menos obscuro, ao mesmo tempo em que estende o campo do desconhecido. Dessa maneira, outros mundos podem ser vislumbrados sem gerar uma aderência à outra perspectiva (tal como fazem aqueles que são "empajezados" ou que se metamorfoseiam), processo que delineia um campo de saber que não é de pleno conhecimento: 
a sombra do desconhecido continua a pairar, o aspecto vago se mantém, estimulando elaborações contínuas e cotidianas sobre as diversas naturezas que se tangenciam.

Como pontua Ingold (2013), a imaginação, em determinado momento da constituição da Ciência Moderna (ao menos em sua dimensão oficial, para sermos cuidadosos com as reflexões acerca da produção do conhecimento científico, conforme Latour [2000]), ${ }^{14}$ foi colocada em oposição aos fatos e condenada, tal como a noção de ficção, a ficar fora do processo de conhecer. Em alguns braços das ciências humanas, em especial nos estudos sobre religião, ${ }_{1}^{15}$ o conceito de imaginação tem sido importante para operar um esfacelamento das grandes divisões modernas. Ingold apresenta alguns exemplos interessantes sobre o que é tido para nós, pretensos modernos, como eventos imaginativos (no sentido de fictício, fabuloso) - por exemplo, os dragões na Idade Média, ou o caso de um jovem ojibwa que se depara com um monstruoso pássaro-trovão - que estão saturados de experiências concretas. Tais experiências foram e são vivenciadas em muitas instâncias e, por isso, são carregadas de densidade sensível, logo, de realidade. Não são, pois, meramente da ordem da metáfora, da representação ou do discurso.

Hughes (2002), no campo das reflexões sobre religião, afirma que a noção de imaginação é fundamental, pois é por meio dela que se pode reconectar a separação material/imaterial, corpóreo/incorpóreo e sujeito/ objeto. Acompanhando as reflexões de um importante pensador muçulmano, Hughes mostra que nas experiências religiosas a imaginação é uma das vias de acesso ao divino: o imaginar possibilita a conexão entre mundos, entre um patamar divino (lunar) e um patamar humano (sublunar). Em suma, o incorpóreo poderia ser experimentado pela posição humana, essencialmente corpórea e material, por meio da imaginação.

Voltando à especificidade do material aqui apresentado, o ponto a ser enfatizado é que a noção de imaginação permite compreender como outros mundos podem ser conhecidos a partir do nosso próprio mundo. Não há, portanto, uma exclusividade das famosas viagens xamânicas, das visões provocadas pelo uso de substâncias propiciatórias (como o tabaco e a ayahuasca), dos sonhos e das músicas-cantos. Outros mundos também podem ser conhecidos se se deixar mergulhar no sensível, percorrendo as vias que comunicam as distintas naturezas, tal como na atenção arrebatadora que Ajãreaty e eu vertemos sobre o caminhar da formiga com sua presa. Com isso não quero afirmar a prevalência da operacionalização da lógica do sensível sobre o xamanismo, ou vice-versa, mas antes apresentar outra rota possível de se conhecer, a qual estabelece uma relação de corroboração e retroalimentação com um modo xamânico concentrado. 
No mais, a noção de imaginação rompe com uma concepção de que o conhecimento se constitui como totalidade. O conhecimento pode ser vago, incerto e alargar o desconhecido. Assim, a imaginação seria um dos dispositivos que permitem um cosmosaber (para fazer uma brincadeira com o emprego stengeriano do termo cosmos) necessário para agir e efetuar uma cosmopolítica.

Enfim, o processo de conhecer perspectivas fora do escopo de um xamanismo concentrado se dá em situações ordinárias, que remetem à capacidade de lidar com esses espaços negros, desconhecidos, na medida em que as pessoas não empajezadas não veem ou percebem a partir da posição de outrem, mas apenas imaginam desde o seu lugar de habitação, por meio de uma economia etoecológica do conhecer.

A comensurabilidade das perspectivas não estaria, dessa forma, garantida apenas pela capacidade xamânica ${ }^{16}$ de transitar entre pontos de vista ou pelo perigo da transformação-captura entre perspectivas (Vilaça 2005), mas também pela possibilidade de imaginar a partir do concreto (no sentido lévi-straussiano) que vaza de uma natureza para a outra.

Se, de um lado, a cultura compartilhada se comunica através do xamanismo, parece-me que, de outro, as naturezas também podem comunicar-se por meio do sensível; são modos de conhecer distintos capazes de se comporem e de se combinarem.

É essa urdidura de mundos - que não gera uma unicidade, mas a multiplicidade de naturezas que se tocam tangencialmente (comunicando-se) — que permite aos Wajãpi produzirem cotidianamente enunciados sobre formas, cheiros, texturas e sons que constituem mundos outros, assim como possibilita nomear elementos de seu mundo próprio a partir desses pontos de contato.

Muitos desses enunciados não são conhecimentos socialmente instituídos (Déléage 2005), ou seja, coletivizados e amplamente reconhecidos, sendo ouvidos da mesma maneira e sem discordância da boca de cada wajãpi. Parecem, ao contrário, criações contextuais - efetivadas por meio de um operador lógico que conjuga o princípio perspectivista, a lógica do sensível e a capacidade imaginativa — para dar inteligibilidade e expressão aos elementos cotidianamente percebidos. A descrição de abertura é exemplar desse processo: quando Ajãreaty sugeriu que a mutuca era anta para a formiga, esta não foi uma concepção estabilizada, um saber instituído, mas a produção de um entendimento momentâneo sobre a cena que nos tomava. Parece tratar-se de uma ação de duplo sentido: conforme se percebe, nomeia-se, conhece-se e, consequentemente, engendra-se um mundo propriamente humano; em sua contramão ${ }^{17}$ se delineiam constantemente mundos outros. 


\section{Um xamanismo do mundo}

Não terá passado despercebida a opção de falar em concentração do xamanismo. Esta formulação permite ser mais fiel a uma concepção wajãpi de que a ação xamânica é baseada em substâncias e capacidades - é um estar, antes que um ser; por isso, opto também por falar em pessoas empajezadas e não em pajés ou em xamãs. Como já destacaram Gallois $(1988,1996)$ e Campbell (1989), o fato de os Wajãpi se referirem a pessoas e seres como ipaje $(i-=$ prefixo de posse de terceira pessoa; - paje = potência xamânica) demonstra que não estamos diante de especialistas, mas de sujeitos que podem concentrar qualidades xamânicas, possuindo alta capacidade de ação. Por isso, é comum ouvir apreciações sobre pessoas ou donos cosmológicos (ijarã) acerca de sua força xamânica, sendo considerados rovijã (chefe, muito grande), wasu (grande), miti (pequeno) ou nipajei (sem pajé).

Como explica Gallois $(1988,1996)$, qualquer um pode experimentar em determinado momento da vida as capacidades xamânicas, pois ao ser soprado (-peju) por alguém empajezado, em um processo de reconstituição do estado de saúde, recebem-se as substâncias (opiwãrã) responsáveis pela cura. Cabe então ao soprado cuidá-las conforme seu interesse em mantê-las ou não em seu corpo.

A ideia de concentração e fixação de substâncias xamânicas, altamente voláteis já que refratárias ao sol quente, ao odor de fluidos corporais, às carnes de aroma forte etc. (Gallois 1988), aparece de forma evidente em diversas etnografias de povos amazônicos. Muitos desses trabalhos se dedicaram a escrutinar o xamanismo devido à sua centralidade, e praticamente constituíram o que podemos chamar de um campo clássico nos estudos amazônicos a investigação de sistemas de cura-agressão que inclui: o tratamento e a mediação da caça; a relação com os mortos e os espíritos de toda sorte; ações de vingança; viagens estáticas por patamares celestes e subterrâneos etc. Em suma, focaram as ações daqueles que são empajezados (convencionalmente denominados de xamãs) (Gallois 1988, 1996); Campbell 1989; Overing 1995; Viveiros de Castro 1986; Chaumeil 1992, 2013; Sztutman 2005; Déléage 2005; Cesarino, 2008, entre muitos outros). Mas esse debate não incorporou de forma significativa as diversas ações cotidianas que não atravessam esse nó potente que é a figura de uma pessoa empajezada. É bem verdade que essa discussão acerca da relação com múltiplas alteridades e o perspectivismo teve desdobramentos significativos no campo do parentesco, especificamente nas reflexões mais recentes sobre a construção de humanos parentes (via idioma da corporalidade) e sobre o problema da afinidade, estabelecendo um elo forte entre parentesco e cosmologia (Viveiros de Castro 2002; Vilaça 2002; Souza 2004). 
A proposta aqui apresentada é olhar para o que está nas bordas do xamanismo, bordas estas que são tão rarefeitas que se perdem de vista, dando a impressão de que não há vida possível fora do xamanismo. Assim, pretende-se refletir acerca do rendimento desse conceito (xamanismo) fora de seu escopo mainstream.

Tomo aqui duas inspirações: a primeira, a etnografia wajãpi e sua qualificação gradativa das ações xamânicas; a segunda, uma discussão teórica sobre formas de classificação. Nesta última, a pesquisa de Bright e Bright (1965) é fundamental, pois são eles que dão um importante passo ao notar que as categorias botânicas de um povo norte-americano (os Yurok) são organizadas por meio de comparações sensíveis que estabelecem uma relação de atração entre elementos semelhantes. Esta proposição é explorada por autores como Hunn (1977) e Rosch \& Lloyd (1978), que apontam para a configuração de categorias classificatórias em torno de núcleos (protótipos), os quais exerceriam uma força centrípeta ao seu redor, criando um campo categorial cuja periferia é rarefeita. Tal concepção desemboca na ideia de um pertencimento gradativo. Proponho olhar o xamanismo como uma categoria analítica organizada em torno de ações centrais que geram essa força centrípeta de atração em relação a determinados fenômenos. Isto implica que os limites do xamanismo são borrados e que há uma inclusão gradativa. A opção é operar com o xamanismo como um gradiente, no qual praticamente não se vê a borda uma vez que a ação xamânica se dilui infinitamente; não se trata, portanto, de uma oposição binária entre xamanismo e não xamanismo.

Por esse caminho talvez possamos pensar que os elementos etnográficos apresentados até o momento dizem respeito a um xamanismo tão diluído que se encontra fora das pessoas (os empajezados ou xamãs - o núcleo do xamanismo). Tratar-se-ia de um xamanismo do mundo, ou melhor, dos mundos, com os quais homens e mulheres wajãpi devem se haver e aprender a manipular em sua vida cotidiana, independentemente de possuírem substâncias xamânicas em seus corpos.

Para seguir essa sugestão é preciso retomar, ainda que de forma breve e superficial, algumas tentativas de circunscrição do xamanismo no contexto das terras baixas da América do Sul e, assim, caracterizar o que seria esse núcleo atrator para, em seguida, apontar as especificidades de um xamanismo wajãpi rarefeito.

Sztutman (2005) faz uma síntese minuciosa e extensiva das descrições da figura do xamã entre povos Tupi. Partindo dos cronistas, o autor afirma que entre os Tupi antigos o xamanismo era uma qualidade disponível a todos os homens e, eventualmente, às mulheres velhas, já na menopausa (:350). 
Era, dessa forma, um atributo distribuído e não uma especialidade. Característica também presente de maneira geral entre grupos ameríndios atuais, segundo Chaumeil (2013) e Sztutman (2005).

Mesmo atentando para a grande variabilidade do xamanismo ${ }^{18}$ amerín- $^{-}$ dio, Sztutman fornece um quadro de traços recorrentes, a saber: os xamãs são pessoas que centralizam as relações com não humanos, sendo que seu reconhecimento se dá por meio da ação e da eficácia, isto é, por um rastro de agência; destaca-se a capacidade intensiva de visão, em alguns lugares os sonhos ganham proeminência, em outros, o uso de bebidas propiciatórias de miragens ou as viagens extracorpóreas, todos dispositivos que permitem ver outros mundos à maneira de outrem; por fim, há uma acepção do xamanismo como ampla comunicação, uma mediação entre distintos estratos do cosmos entre humanos e não humanos, entre parentes e inimigos.

Para fazer tais transições e conexões comunicativas, o xamã necessita de um corpo híbrido, intencionalmente construído para tal fim. Os xamãs são seres "interespecíficos" (Viveiros de Castro 2002), "situam-se entre os homens e os não humanos" (Sztutman 2005:367). Eles são figuras da mediação e, por isso, agentes privilegiados de uma política cósmica.

Parte das considerações de Sztutman segue a rota inicialmente traçada por Viveiros de Castro. Segundo este último autor:

O xamanismo amazônico pode ser definido como a habilidade manifesta por certos indivíduos de cruzar deliberadamente as barreiras corporais e adotar a perspectiva de subjetividades alo-específicas, de modo a administrar as relações entre estas e os humanos. [...] O encontro ou o intercâmbio de perspectivas é um processo perigoso, é uma arte política - uma diplomacia (Viveiros de Castro 2002:357-358).

Em sentido semelhante, Chaumeil (2013:112) acrescenta com precisão que, para situar o xamanismo no centro do fazer político, ele não deve ser restringido à mediação, mas sim ter seu caráter transformacional ressaltado. Seguindo certa tradição intelectual, o domínio do político deixa de ser tratado como representação e passa a ser entendido como ação.

Não por acaso o xamã é apresentado como o alicerce da ontologia perspectivista, afinal, ele experimenta, vê a aparência oculta dos seres, sendo a reportação de sua vivência o mecanismo de validação do conhecimento de outros universos. Tais perspectivas, por sua vez, devem manter-se separadas, "[a]penas os xamãs, que são como andróginos no que respeita à espécie, podem fazê-las comunicar, e isso sob condições especiais" (Viveiros de Castro 2002:378). 
Nesse panorama é preciso mencionar também a afamada tipificação de Hugh-Jones (1996) acerca de duas formas opostas e complementares de xamanismo - o vertical e o horizontal. O caso exemplar desta proposição são os povos do Alto Rio Negro, onde figuram as funções denominadas (com variação) de -payé e -kubu, também chamadas em português local como benzedor e xamã. Grosso modo essas figuras concentram ações em extratos diversos: o xamanismo horizontal (-payé) se dedica às relações com habitantes da floresta, intercedendo nas atividades de caça, pesca, guerra etc. e realiza cura por meio de ações sobre o corpo; o xamanismo vertical ( $-k u b u)$ concentrar-se-ia nas relações com os ancestrais e os seres míticos, tendo seu foco de ação fora do corpo dos doentes. Em ambos os casos, mais uma vez o que se destaca é a potência de relação e ação entre seres diversos ou, como insiste Viveiros de Castro em uma crítica a essa dualidade cartesiana, trata-se de um xamanismo transversal no qual se destaca "um modo de comunicação entre heterogêneos" (2008:80).

Esse traço comunicativo que marca o xamanismo ameríndio é tratado por Carneiro da Cunha (1998) como uma capacidade de tradução, entendida como um processo complexo de recriação, inovação e transformação (1998:12-13). A autora toma como inspiração a noção bejaminiana, donde a boa tradução é aquela que consegue transmitir em outra língua (deformando-a) a intenção de quem fala. Enfatiza-se a importância da poética xamânica construída sobre "palavras torcidas" em práticas de canto e discurso, que não só permitem a comunicação entre mundos, como também a expressão de um mundo outro e suas possibilidades de (inter)ação. A poética xamânica e sua peculiar relação com a tradução foram tratadas de modo exemplar por Cesarino (2008) e Towsley (1993).

Mas o xamanismo também pode prescindir do xamã, como no caso Guajá (Garcia 2010) e Parakanã (Fausto 2001). Ao apresentar o caso Parakanã, Fausto (2001) o caracteriza como "um xamanismo sem xamãs", já que a capacidade de agência não se apresenta cristalizada sobre figuras especializadas, mas se efetiva por meio dos sonhos (entendidos nesse contexto como uma experiência onírica com o outro, com o inimigo): "Todo mundo que sonha tem um pouco de -pajé e alguma ciência para curar. Porém, não se é jamais xamã, pois este lugar não pode ser ocupado senão provisoriamente [...]" (:341). Ainda assim, mesmo sem a figura máxima do xamanismo, há evidentes momentos e circunstâncias de concentração, tal como a existência da posição de feiticeiro - alguém que controla agentes patogênicos eficazes. Esta é uma presença forte nos limites das facções parakanã, onde as acusações de feitiço são constantes. Por isso o autor afirma que capacidades altamente xamânicas, como técnicas de sucção para retirada de patógenos, "são antes um estigma do que 
uma honraria" (:337). Nesse contexto, mesmo que não se fixe sobre pessoas de modo exclusivo, o xamanismo se apresenta nos sonhos, em processos de nominação, recebimento de cantos e na feitiçaria (Fausto 2001), todos momentos de materialização e concentração da ação xamânica.

Ainda que as descrições até aqui apresentadas não se refiram a ações de pessoas empajezadas, não estamos diante de um xamanismo sem xamã, tal como descrito por Fausto. O xamanismo wajãpi é muito bem traçado em seu escopo clássico pelos trabalhos de outros pesquisadores (Gallois 1988, 1996; Campbell 1989), sendo as pessoas ipajé centrais em processos de cura-agressão. Contudo, não se pode enxergar nos exemplos apresentados neste artigo uma operacionalização típica desse cenário. Ou seja, não se vê neles a transformação alo-específica, as capacidades de visão intensiva, a manipulação de propriedades da pessoa, a constituição de um corpo híbrido, as ações de vingança e agressão típicas dos sistemas xamânicos descritos por esses emblemáticos trabalhos. Apesar disso, seria possível pensá-los como uma forma xamânica?

Nesse sucinto balanço parece que uma das características principais desse complexo xamânico ameríndio é a comunicação entre heterogêneos, entre seres diversos. Nesse caso, poderia ser proveitoso seguir com o termo xamanismo para experimentar seu rendimento fora do centro de concentração, isto é, sem abordar a perspectiva dos sujeitos empajezados e suas ações de cura, doença-feitiçaria, viagens estáticas etc. Em suma, o problema a ser percorrido é: qual a possibilidade de tratar as descrições etnográficas apresentadas até o momento como um xamanismo rarefeito, ${ }^{19}$ tão diluído a ponto de se chegar a perder de vista os sujeitos da ação?

\section{Comunicações sensíveis}

Os índices concretos permitem não apenas conhecer outras perspectivas fora das ações xamânicas concentradas, como também operar uma cosmopolítica, isto é, uma forma de inter-ação com uma miríade de sujeitos e seus respectivos mundos. No âmbito de um xamanismo rarefeito, sugiro que as relações com tantos outros habitantes do cosmos se dão por meio do concreto e, muitas vezes, independem de um sujeito humanamente marcado. Sons, formas, gostos, texturas e cheiros vazam e criam uma outra rota de comunicação e de ação entre perspectivas, a qual pode ser independente da intenção de seus sujeitos.

Alhures (Cabral de Oliveira 2012) descrevi certos procedimentos extremamente recorrentes entre famílias wajãpi ${ }^{20}$ nos quais se vertem sobre as 
crianças cuidados que visam capacitá-las para saberes e tarefas altamente valorizadas: untar os tornozelos de neófitos com banha de anta para que eles consigam andar grandes distâncias, suportando a carga dos pesados panakó (mochilas feitas de folha de palmeiras), tal como o tapir que caminha sustentando o enorme peso de seu corpo; ingerir a língua de japiim (Cacicus ssp.) para facilitar o aprendizado de idiomas estrangeiros, já que esta ave é conhecida por imitar cantos de outros pássaros; lavar as mãos dos meninos com um macerado de jãkãsï'ï (Acrocinus longimanus), besouro que rói madeira dura, para que, quando adultos, eles sejam exímios derrubadores de roça; colocar pedaços da garra de gavião real (Harpia harpyja) no colar de um filho para que ele seja grande caçador etc. Tais ações são sempre acompanhadas de falas que enunciam a captura e o recorte do aspecto pretendido; trata-se de uma aproximação parcial e controlada com determinados não humanos.

Ações como estas são feitas também em outros âmbitos. A confecção do roçado, por exemplo, está envolta em procedimentos semelhantes. É comum usar uma espécie vegetal encontrada na mata, mutukuru, que possui grandes raízes tuberosas, para alegrar as plantações e assim aumentar a qualidade e a quantidade da colheita de tubérculos. Nesse caso, a água com a raiz de mutukuru ralada é aspergida sobre a plantação e acompanhada de uma fala eficaz. ${ }^{21}$ "Tapo katu kene mani'o ije ne mutukuru eu / Ti'a katu kene jity ije ne mutukuru eu..." ["Para que você dê boas raízes mandioca, eu peço à mutukuru / Para que você dê bons frutos batata, eu peço à mutukuru..."]. Ao plantar pimentas se recorre a alguns cuidados, ao enterrar as sementes se diz: " akyky si'u / kwata si'u / taitetu si'u..." ["Que comamos guariba/ Que comamos coatá / Que comamos caititu..."].

Falas como estas são também executadas na pescaria com timbó (Lonchocarpus chrysophyllus) e kunami (Clibadium sylvestre). Ao colocar o macerado de plantas no igarapé, deve-se exortar cada tipo de peixe a se embriagar com o que para eles é caxiri. Já na coleta de castanha, ao adentrar o castanhal, as castanheiras são chamadas de avós; após essa aproximação familiarizante, se pede que esses avós não joguem suas sapucaias sobre as cabeças dos coletores.

Os exemplos de ações e falas eficazes que envolvem as atividades cotidianas ligadas ao roçado, à pesca, à coleta e à caça são extensos, mas estes são suficientes para demonstrar como a urdidura da vida está envolta em cuidados e mediações. Tais procedimentos, amplamente conhecidos por todos os Wajãpi, remetem a modos de ação e negociação com entes não humanos que não passam pelo vértice das pessoas empajezadas. Parece tratar-se de um xamanismo difuso, na medida em que não incide sobre a concentração de substâncias xamânicas próprias ao corpo híbrido de sujeitos empajezados. Isto se evidencia não só na presença constante de tais condutas, mas também em uma comunicação cruzada entre mundos à revelia de seus sujeitos. 
Uma conversa ${ }^{22}$ que tive com Ajãreaty (A) e seu marido Marãte (M) ilustra bem o modo não só como os cheiros são sorvidos por diversos seres, tratando-se de odores propriamente distintos, como também a maneira pela qual o sensível faz comunicar perspectivas:

A - Quando a gente carrega arara, e depois toma banho no rio, moju [sucuriju, dono da água] vai sentir o cheiro de arara, ele vai ficar bravo conosco. Ele não gosta de cheiro de arara, vai nos matar. Cheiro de guariba ele não gosta, de coatá... Já cheiro de anta ele gosta, caititu ele gosta, veado ele gosta também... Por que será? Cutia é bom, só coatá, arara e macaco quando cortamos não podemos banhar, nossos parentes devem trazer água para nos banharmos. Só por um dia. Você entendeu?

J - Sim, entendi. E urucum, moju também não gosta?

A - Ele não suporta cheirá-lo. Mas não mata ninguém [por causa do cheiro de urucum]... Breu branco a mesma coisa, ele não suporta cheirar também. Por isso wajãpi se unta com urucum, nosso rosto nós o tornamos vermelho. Breu branco para ele é catinga, tal como o fétido cheiro de mucura, que nós não suportamos sentir.

M - Você agora você gostaria de cheirar gasolina? Vai fazer sua cabeça doer, "hummm não suporto cheirar" você vai dizer. É a mesma coisa [para moju]. Você entendeu?

Os cheiros atravessam as distintas perspectivas, vazam de um mundo a outro, e instituem uma comunicação a despeito das vontades de seus sujeitos. Por isso é preciso estar atento a eles e tomar os devidos cuidados, o que supõe conhecer os gostos olfativos dos demais habitantes do cosmos. Conhecimento que, sem dúvida, constitui-se por diversas rotas que se combinam: a experiência reportada por pessoas empajezadas, as narrativas míticas, o adoecer e (o que pretendo acrescentar aqui) o mergulho atento no sensível.

Tal como os cheiros, outros perceptos também podem estabelecer comunicações cruzadas. Ao fazer uma caminhada de uma aldeia à outra, acompanhada de uma velha wajãpi, o bando de crianças que nos seguia começou a jogar pedras em uma lagoa às margens do caminho. A mais velha delas repreendeu: "Não joguem! A chuva vai cair!"23 Perguntei à velha porque iria chover e ela explicou: "O dono [da água, moju] não gosta. Se nós jogamos pedras na água, ele vai ouvir e vai ficar bravo". O dono da água não gosta do barulho das pedras caindo em sua morada, assim como não aprecia o cheiro de sangue das mulheres menstruadas ou parturientes; já jurupari ou ãjã (manifestações ligadas ao espectro dos mortos e aos donos, respectivamente) são justamente atraídos por tais aromas, os quais lhes são 
agradáveis. O sensível vai, dessa forma, tecendo uma comunicação entre mundos por vezes à revelia de seus sujeitos.

Pelo viés do concreto, que atravessa e conecta as múltiplas naturezas, ocorrem também capturas e agressões por parte dos donos da floresta (ka'a jarã). Barulhos arrebatadores, cheiros inebriantes ou visões terrificantes estão ligados tanto a pessoas que se perdem na mata como àquelas que são acometidas por um estado denominado -awyry, em que uma pessoa passa gradativamente a perceber o mundo à maneira de outrem (Cabral de Oliveira 2012), agressão que lembra em muito o -jepota guarani, no qual um indivíduo é seduzido e se transforma em animal (Macedo 2009), bem como os processos de captura e metamorfose de caçadores wari (Vilaça 2005) e o perigo de enamorar-se por um desconhecido na floresta, conforme relatos jarawara (Maizza 2014).

Sentir o perfumado cheiro do urucum de moju, como ocorreu em um trajeto pela floresta, é razão para apertar o passo. Deixar-se sorver o adocicado perfume pode implicar uma passagem de ida ao universo do dono da água. Esse índice sensível, ainda que percebido de maneira diferente por humanos e sucuris, tratando-se portanto de perceptos propriamente distintos (ainda que semelhantes), opera uma passagem entre mundos. Daí a importância do uso de resinas cheirosas e revestimentos corporais, que como índices olfativos e imagéticos operacionalizam as relações entre sujeitos, promovendo nesse caso uma proteção por meio do afastamento, como explicava Ajãreaty.

Em suma, parece que a cosmopolítica é também realizada por um idioma do sensível, que permite tanto operacionalizar as relações com outros sujeitos (produzir efeitos de afastamento, sedução, agressão, alegria e transformações), quanto efetivar comunicações entre mundos, independentemente da intenção de seus sujeitos e sem recorrer aos afamados recursos xamânicos, como o uso de tabaco, a ingestão de ayahuasca, o chacoalhar do maracá, o sonhar, as viagens realizadas por um corpo interespecífico, o uso de cantos e músicas.

\section{A poesia concreta dos mundos}

Na concepção de Bateson, o mundo vivente está conectado por uma rede pela qual circulam informações (relações de diferença). ${ }^{24}$ Essa malha que emaranha os diversos entes possui ordem(ns), o que ele denomina de "padrões que conectam" (patterns of connection). ${ }^{25}$ Aqui a estética recebe um status especial: a vida é compreendida como intrinsecamente bela e organizada. Essa estética sensível (em uma acepção lévi-straussiana) é entendida como um nível de comunicação: a organização da matéria viva é em si produto e 
produtora de informações. Para citar um de seus muitos exemplos: "A anatomia do caranguejo é repetitiva e rítmica. Como a música, ela é repetitiva com modulação" (Bateson 1979:10).

Essa noção de estética, que está atrelada à ideia de ordem(ns), de padrão(ões), que constitui desde um organismo, passando por um sistema de parentesco, até a estrutura de um cristal, é um dos caminhos tomados tanto por Bateson como por Lévi-Strauss $(1970,2011)$, para falar de uma natureza ordenada e bela, que se faz ouvir, que se faz ver, sentir, sorver.. Se acompanharmos o raciocínio de ambos os autores, juntamente com uma concepção wajãpi, só poderemos multiplicar essa agência pelos muitos mundos. Não é, pois, de estranhar que esses mundos se comuniquem à revelia de seus sujeitos e pelo sensível.

Nesse apanhado heterogêneo de pequenas descrições etnográficas, foram iluminadas as ações de tessitura do cotidiano que não passam pelo vértice de pessoas empajezadas, mas dizem respeito antes a uma atenção voltada ao sensível, a um interesse de debruçar-se sobre um mundo que acaba por se desdobrar em outros.

A opção por tratar esse conjunto etnográfico como uma variação do xamanismo, a qual qualifiquei como rarefeita, deve-se ao anseio de ressaltar a importância e a eficácia de atos tão singelos e ordinários. Tais ações não estão atreladas a uma potência xamânica autoevidente, mas se referem a um fazer e a um cuidar da vida social por meio de negociações constantes com a multiplicidade de habitantes do cosmos. É nesse sentido que a ideia de uma cosmopolítica operada através do sensível ganha relevo: o jeito de nomear os vegetais, os cuidados vertidos sobre crianças e roçados, os enunciados sobre outras perspectivas e as falas eficazes são formas de relacionar-se com distintas alteridades e seus respectivos mundos, algo necessário à boa vida.

Nesse processo destaca-se uma ação própria dos mundos: eles podem comunicar-se independentemente de seus sujeitos. Os mundos se comunicam pelo sensível, estabelecem uma verdadeira linguagem poética ${ }^{26}$ através do concreto. Trata-se de naturezas que se tangenciam, que se sobrepõem e que, como placas tectônicas, se chocam em determinados momentos. Tais processos são eminentemente comunicacionais: fornecem informações (no sentido de Bateson [1979], como uma diferença) que permitem aos Wajãpi imaginarem outras perspectivas e operarem uma cosmopolítica cotidiana, ou seja, nomear, negociar e se relacionar com outros seres sem a necessidade de aderir ou viajar pela perspectiva de outrem. Tudo é feito a partir do dispositivo de imaginação e da manipulação do sensível, um sensível que aparece como um idioma poético dos mundos. 
Recebido em 23 de julho de 2014

Aprovado em 30 de novembro de 2014

Joana Cabral de Oliveira é pós-doutoranda do Instituto de Biociências da Universidade de São Paulo. E-mail: joanacoliveira2@gmail.com

\section{Notas}

${ }^{1}$ Este artigo vem sintetizar e rever alguns dos pontos abordados ao longo das pesquisas de mestrado, doutorado e pós-doutorado. As descrições aqui apresentadas foram baseadas em um trabalho de campo de aproximadamente 15 meses, sem contar o tempo dedicado às atividades indigenistas realizadas no âmbito do Programa Wajãpi, da ONG Iepé, experiência que foi fundamental para adquirir proficiência na língua wajãpi e compreensão desse universo.

${ }^{2}$ Língua do tronco Tupi, da família Tupi-Guarani.

${ }^{3}$ Vale notar que as etnografias sobre os Wajãpi (Gallois 1988; Grenand 1980) apresentavam descrições que viriam a somar dados para a elaboração do conceito de perspectivismo, sendo citados no material etnográfico arrolado por Viveiros de Castro (2002).

${ }^{4}$ Há muitas noções de metáfora que poderiam ser usadas.A recusa em usá-la aqui se dirige à noção mais corrente que é caracterizada como uma figura de linguagem, do âmbito da representação e não do mundo e do corpo. Contudo, é preciso pontuar que o modo como alguns autores tratam a metáfora, em especial George Lakoff (1990), que aborda suas relações com o corpo (falando de uma mente encorporada - embodied mind), explora como as metáforas podem ser importantes na constituição de realidades. Allan Passes (2006) usa esse conceito de metáfora no campo etnográfico amazônico, demonstrando a rentabilidade dessa abordagem para a etnologia ameríndia. Esta parece ser uma pista interessante a ser explorada em outro momento: uma compreensão da metáfora da ordem do mundo, enraizada no corpo, talvez seja um caminho viável para descrever os processos de constituição de múltiplos mundos, de muitas realidades.

${ }^{5}$ Ãjã é uma categoria comum em várias cosmologias tupi, tendo sido descrita por diversos autores. Gallois (1988) a traduz, inspirada na etnografia de Viveiros de Castro (1986), como "efeito espírito". Isto porque ãjã não se refere a uma categoria de seres, mas sim a uma das formas manifestas dos ijarã (os donos cosmológicos) e de alguns espíritos. A descrição dos Wajãpi sobre os ãjã é recorrentemente a de uma aparência monstruosa, luminescente e de odor forte. 
${ }^{6}$ A noção de índice remete necessariamente a Charles Peirce, que o define como um signo indicador a partir do qual podem ser feitas inferências (apud Gell 1988). Na proposta de antropologia da arte de Alfred Gell, o autor acrescenta ao conceito peirciano uma carga semântica de agentividade. Eduardo Kohn (2013), por sua vez, também toma de empréstimo o conceito de Pierce na proposição de uma "antropologia para além do humano", na qual a linguagem passa por uma "provincialização" (:3842) e deixa de ser um atributo exclusivo do homem. Segundo Konh, a propriedade característica do índice é sua capacidade de significar mais do que ele representa, contrapondo-se à noção de ícone que representa a si mesmo (:32-33).

${ }^{7}$ O jurupari é uma manifestação aterrorizante que causa doenças. Ele também é associado ao espectro terrestre dos mortos, logo, à podridão.

${ }^{8}$ Note-se que essa similaridade entre o tipiti e a sucuri tem grande rendimento na região das Guianas, tendo sido abordada de modo belíssimo no trabalho de Lucia van Velthem (2003) entre os Wayana.

${ }^{9}$ As rãs e os sapos são agrupadas sob o rótulo amãna warã (amantes da chuva) ou também amãna reima (xerimbabos da chuva). São eles que marcam sonoramente esse período e possuem uma relação forte com as águas celestes.

${ }^{10}$ Estrutura que lembra o formato de estames (órgão masculino), mas que não são órgãos reprodutores. Trata-se daqueles filamentos coloridos que chamam a atenção nas flores de maracujá.

${ }^{11}$ Estrutura que suporta androceu e gineceu, as partes masculinas e femininas. Aspecto característico do gênero Passiflora.

${ }^{12}$ Disposição em forma de coroa das estruturas masculinas (estames) e femininas (pistilos).

${ }^{13}$ De base redonda.

${ }^{14}$ Um bom exemplo da função imaginativa nas Ciências Modernas é o caso da descrição da estrutura da dupla hélice do DNA por Watson e Crick, descrita por Latour (2000).

${ }^{15}$ Em uma busca sobre o uso do conceito de imaginação na antropologia em dois importantes periódicos - Current Anthropology e Journal Royal Anthropological Institute - só achei referências ao termo em estudos do campo da religião.

${ }^{16}$ Refiro-me aqui a uma compreensão alargada de xamanismo, não restrita apenas à figura do pajé, mas às diversas experiências que envolvem esse complexo, tais como: sopro-cura; viagens oníricas; ataques de agentes agressores...

${ }^{17}$ Uma clara inspiração no processo de invenção e contrainvenção descrito por Roy Wagner (2009). 
18 "Ora, o xamanismo é encontrado, conforme passamos por entre lugares e contextos diversos, sob uma 'geometria [bastante] variável' (Chaumeil 1992): ora associado à guerra e à agressão, ora associado à convivialidade; ora um assunto público, ora algo que deva ser realizado discretamente; ora a baixa relevância de figuras reconhecidas como xamãs, ora a emergência de xamãs muito reputados [...]" (Sztutman 2005:361).

${ }^{19}$ A ideia de um xamanismo rarefeito aqui apresentada não pretende figurar como um tipo ideal, tal qual fez Hugh-Jones (1996) em sua oposição vertical-horizontal. Trata-se apenas de uma qualificação que pretende antes ressaltar um contínuo xamânico entre um polo de concentração máxima e outro de concentração mínima, num universo onde o xamanismo parece não ter fim, diluindo-se ad infinitum.

${ }^{20}$ Sua importância e recorrência são evidentes e foram apresentadas de outras formas nos trabalhos de Gallois (1988) e Rosalen (2005).

${ }^{21}$ É importante notar que não se trata de uma fórmula e essa fala varia inclusive quando a mesma pessoa a executa. É apenas uma fala eficaz que explicita e direciona a intenção da ação.

${ }^{22}$ O diálogo apresentado foi conduzido em língua wajãpi, sendo apenas mostrada a versão em português de uma tradução por mim realizada.

${ }^{23}$ As frases aqui reproduzidas também são uma tradução minha do wajãpi para o português.

${ }^{24}$ Este tema ganhou relevo atualmente com a publicação de How forest think, de Eduardo Kohn (2013). Contudo, optei por não aplicar sua proposta analítica, ainda que seja possível enxergar muitas similaridades entre a etnografia aqui apresentada e o trabalho de Kohn. A proposta de Bateson, além de anterior, parece-me mais libertária, uma vez que não propõe uma grade instrumental fechada, mas antes fornece elementos para uma reflexão ampla, em que as proposições conceituais é que devem estar sujeitas à etnografia; algo que se alinha à proposta cosmopolítica de Stengers.

${ }^{25}$ É preciso estar atento para o fato de que a noção de padrão de Bateson implica transformação: padrão é como "uma dança de partes que interagem e só secundariamente restringida por vários tipos de limites [...] por aqueles limites que os organismos [...] impõem" (1986:21). Nesse sentido, aproxima-se muito da noção de estrutura de Claude Lévi-Strauss.

${ }^{26}$ A noção de poética aqui empregada visa apenas marcar o caráter estético presente nessas operações sensíveis. Contudo, poderia ser feita uma interessante reflexão sobre o uso da noção de poética para caracterizar o que foi descrito até aqui, especialmente tendo em vista a discussão de Pedro Cesarino (2008) sobre uma poética que se faz presente nos mito-cantos marubo. Cesarino vai buscar em Roman Jakobson uma definição da linguagem poética para fundamentar sua opção por tratar os mito-cantos e a linguagem xamânica marubo como poesia. Desse diálogo (entre 
o material marubo e a teoria de Jakobson), Cesarino ressalta a ambiguidade de uma mensagem que é centrada em si mesma. Voltando ao caso de abertura, a incerteza e a ambiguidade estão presentes no comentário de Ãjareaty acerca da relação entre formiga e mutuca. Como pontuado ao longo deste artigo, estamos defronte de enunciados exploratórios, incertos, que ampliam o escopo do desconhecido. Vale notar ainda que as narrativas míticas são repletas de metáforas e de analogias que operacionalizam cadeias de relações sensíveis entre elementos heterogêneos. Para algumas considerações sobre esta questão e o registro de mitos wajãpi, ver Cabral de Oliveira (2012) e Gallois (1988).

\section{Referências bibliográficas}

BATESON, Gregory. 1979. Mind and nature. A necessary unity. New York: E. P. Dutton. 1986. Mente e natureza. Uma unidade necessária. Rio de Janeiro: Francisco Alves.

BRIGHT, J. \& BRIGHT, W. 1965. “Semantic structures in northwestern California and the Sapir-Worf hypothesis". American Antrhopologist, 89:914-919.

CABRAL DE OLIVEIRA, Joana. 2012. Entre plantas e palavras. Tese de Doutorado, Universidade de São Paulo, Programa de Pós-Graduação em Antropologia Social.

CAMPBELL, Allan Tormaid. 1989. To square with genesis. Edinburgh: Edinburgh University Press.

CARNEIRO DA CUNHA, Manuela. 1998. "Pontos de vista sobre a floresta amazônica: xamanismo e tradução". Mana. Estudos de Antropologia Social, 4(1):7-22.

CESARINO, Pedro N. 2008. Oniska: a poética da morte e do mundo entre os Marubo da Amazônia ocidental. Tese de Doutorado, PPGAS/Museu Nacional/UFRJ.

CHAUMEIL, Jean-Pierre. 1992. "Varieties of Amazonian shamanism". Diogenes, 158:101-113.
— 2013. "Une façon d'agir dans le monde. Lechamanismeamazonien". In: K. Buffretille et al. (orgs.), D'une anthropologie du chamanisme vers une anthropologie du croire. Hommage à l'oeuvre de Roberte Hamayon. Paris: Centre d'Études Mongoles et Sibériennes/École Pratique des Hautes Études. pp. 109-134.

DÉLÉAGE, Pierre. 2005. Le chamanisme Sharanahua. Tomé 1 . Thèse de doctorat, École des Hautes Etudes en Sciences Sociales, Paris.

FAUSTO, Carlos. 2001. Inimigos fiéis. História, guerra e xamanismo na Amazônia. São Paulo: Edusp.

GALlOIS, Dominique Tilkin. 1986. Migração, guerra e comércio: os Waiãpi na Guiana. São Paulo: FFLCH-USP. . 1988. O movimento na cosmologia waiapi: criação, expansão e transformação do universo. Tese de Doutorado, Programa de Pós-Graduação em Antropologia Social, Universidade de São Paulo.

. 1996. "Xamanismo waiãpi: nos caminhos invisíveis, a relação i-paie". In: E. Jean Matteson Langdon (org.), Xamanismo no Brasil. Novas perspectivas. Florianópolis: Editora da UFSC. pp. 39-74. 
GARCIA, Uirá. 2010. Karawara. A caça e o mundo dos Awá-Guajá. Tese de Doutorado, Programa de Pós-Graduação em Antropologia Social, Universidade de São Paulo.

GELL, Alfred. 1988. Art and agency. An anthropological theory. Oxford: Clarendo Press.

GOW, Peter. 2001. An Amazonian myth and its history. Oxford: Oxford University Press.

GRENAND, Pierre. 1980. Introduction a l'étude de l'univers Wayãpi. Paris: Centre National de la Recherche Scientifique.

HUGHES, Aaron. 2002. "Imagining the divine: Ghazali on imagination, dreams, and dreaming". Journal of the American Academy of Religion, 70(1):33-53.

HUGH-JONES, Stephen. 1996. "Shamans, prophets, priests and pastors". In: N. Thomas et al. (orgs.), Shamanism, history, and state. Ann Arbor: University of Michigan Press. pp. 32-75.

HUNN, Eugene. 1977. Tzeltal folk zoology - the classification of discontinuities in nature. New York: Academic Press.

INGOLD, Tim. 2000. The perception of the environment. Essays on livelihood, dwelling and skill. London: Routledge. . 2013. "Dreaming of dragons: on the imagination of real life". Journal Royal Anthropological Institute, 19(4):734-752.

KOHN, Eduardo. 2013. How forests think: toward an anthropology beyond the human. New York: Paperback.

LAKOFF, George.1990. Women, fire and dangerous things. What categories reveal about the mind. Chicago: The University of Chicago Press.

LATOUR, Bruno. 2001. A esperança de Pandora. Bauru: Edusc.

- 2000. Ciência em ação. Como seguir cientistas e engenheiros sociedade afora. São Paulo: Unesp.

LÉVI-STRAUSS, Claude. 1970. O pensamento selvagem. São Paulo: Ed. Universidade de São Paulo.
_ 2004. O crue o cozido. São Paulo: Cosac \& Naify.

- 2011. O homem nu. São Paulo: São Paulo: Cosac \& Naify.

LIMA, Tânia. Stolzen. 1996. "O dois e seu múltiplo. Reflexões sobre o perspectivismo em uma cosmologia Tupi". Mana. Estudos de Antropologia Social, 2(2):21-47.

. 2002. "O que é um corpo?". Religião e Sociedade, 22(1):09-19.

_. 2005. Um peixe olhou para mim. São Paulo: Ed. Unesp.

MACEDO, Valéria. 2009. Nexos da diferença. Cultura e afecção em uma aldeia guarani na serra do Mar. Tese de Doutorado, Programa de Pós-Graduação em Antropologia Social, Universidade de São Paulo.

MAIZZA, Fabiana. 2014. "Sobre as crianças-planta: o cuidar e o seduzir no parentesco Jarawara". Mana. Estudos de Antropologia Social, 20(3):491-518.

OVERING, Joanna. 1995. "O mito como história: um problema de tempo, realidade e outras questões". Mana. Estudos de Antropologia Social, 1(1):107-140. - 2006. "O fétido odor da morte e os aromas da vida. Poética dos saberes e processo sensorial entre os Piaroa da bacia do Orinoco". Revista de Antropologia, 49(1):19-54.

PASSES, Allan. 2006. "Do um à metáfora. Para um entendimento da metáfora pa'ikwené (palikur)". Revista de Antropologia, 49(1):245-281.

RIVAL, Laura. 1993. "The growth of family trees: Huaorani conceptualization of nature and society". Man, 28(4):635652.

2001. "Seed and clone: the symbolic and social significance of bitter manioc cultivation". In: Laura Rival \& Neil Whitehead (eds.), Beyond the visible and the material: the amerindization of society in the work of Peter Rivière. Oxford: Oxford University Press. pp. 57-80. 
ROSALEN, Juliana. 2005. Aproximações à temática das DST junto aos Wajãpi do Amapari. Um estudo sobre malefícios, fluidos corporais e sexualidade. Dissertação de Mestrado, Programa de Pós-Graduação em Antropologia Social, Universidade de São Paulo.

ROSCH, Eleanor \& LLOYD, B.B. 1978. Cognition and categorization. Hillsdale, N. J.: Lawrence Erlbaum Associates. VAN VElTHeM, Lúcia Hussak. 2003. O belo é a fera. A estética da produção e da predação entre os Wayana. Lisboa: Assírio \& Alvim.

SOUZA, Marcela Coelho de. 2004. "Parentes de sangue: incesto, substância e relação no pensamento timbira". Mana. Estudos de Antropologia Social, 10(1):25-60.

STENGERS, Isabelle. 2005. "The cosmopolitical proposal". In: B. Latour \& P. Weibel (orgs.), Making things public: atmospheres of democracy. Cambridge: MIT Press. pp. 994-1003.

SZTUTMAN, Renato. 2005. O profeta e o principal: a ação política ameríndia e seus personagens. Tese de Doutorado, Programa de Pós-Graduação em Antropologia Social, Universidade de São Paulo.

TAYLOR, Anne Christine. 2001. "Wives, pets, and affines: marriage among the Jovaro". In: Laura Rival \& Neil Whitehead (eds.), Beyond the visible and the material: the amerindization of society in the work of Peter Rivière. Oxford: Oxford University Press. pp. 45-56.

TOWSLEY, G. 1993. "Song paths. The ways and means of Yaminahua shamanic knowledge". L'Homme, 126128:449-468.

VILAÇA, Aparecida. 2002. "Making kin out of others in Amazonia". Journal of the Royal Anthropological Institute, 8(2):347-365. - 2005. "Chronically unstable bodies: reflections on Amazonian corporali- ties". Journal of the Royal Anthropological Institute, 11(3):445-464.

VIVEIROS DE CASTRO, Eduardo. 1986. Araweté: os deuses canibais. Rio de Janeiro: Jorge Zahar/Anpocs. - 2002. A inconstância da alma selvagem. São Paulo: Cosac \& Naify. - 2008. "Xamanismo transversal". In: R. C. Queiroz \& R. F. Nobre (orgs.), Lévi-Strauss, leituras brasileiras. Belo Horizonte: Ed. UFMG. pp. 79-124. WAGNER, Roy. 2009. A invenção da cultura. São Paulo: Cosac \& Naify. 


\section{Resumo}

Tendo como base uma pesquisa etnográfica entre famílias wajãpi (grupo Tupi, que habita a bacia do rio Jari-AP), este artigo aborda alguns temas candentes na etnologia das terras baixas da América do Sul por uma rota diversa: examinarei o perspectivismo ameríndio e o xamanismo a partir das relações cotidianas de pessoas não "empajezadas" com seres não humanos, em especial com as plantas. Por esse caminho etnográfico emergem questões acerca de como o mundo de outrem pode também ser conhecido fora do afamado vértice xamânico, passando por distintos dispositivos de conhecimento, tais como: a "lógica do sensível", a capacidade imaginativa e a existência de passagens entre naturezas, as quais permitem uma comunicação em amplo sentido - o que proponho caracterizar como um xamanismo rarefeito. Palavras-chave Cosmopolítica, Wajãpi, Imaginação, Xamanismo rarefeito, Lógica do sensível.

\section{Abstract}

Based on ethnographic research among the Wajãpi (Tupi speaking people, Amapá State, Brazil), this article takes a different tack to central issues in the ethnology of lowland South America: it examines Amerindian perspectivism and shamanism through the lens of quotidian relations of non-shamans with non-human beings, in particular with plants. This line of inquiry raises questions about how the world of others can be apprehended outside of the famous shamanic vertex, exploring other knowledge devices, such as the "logic of the sensible", imaginative capacity, and the existence of passages between natures, all of which enable communication in a general sense - a condition I call a "rarefied shamanism". Key words Cosmopolitcs, Wajãpi, Imagination, Rarefied shamanism, Logic of the sensible. 